Article

\title{
Wind Speed Prediction Using a Univariate ARIMA Model and a Multivariate NARX Model
}

\author{
Erasmo Cadenas ${ }^{1}$, Wilfrido Rivera ${ }^{2, \dagger}$, Rafael Campos-Amezcua ${ }^{2, *, \dagger}$ and Christopher Heard ${ }^{3, \dagger}$ \\ 1 Facultad de Ingenieria Mecanica, Universidad Michoacana de San Nicolas de Hidalgo, \\ Santiago Tapia No. 403, Col. Centro, CP 58000 Morelia, Michoacan, Mexico; ecadenas@umich.mx \\ 2 Instituto de Energias Renovables, Universidad Nacional Autonoma de Mexico, Apartado postal 34, \\ CP 62580 Temixco, Morelos, Mexico; wrgf@ier.unam.mx \\ 3 Division de Ciencias de la Comunicacion y Diseno, Departamento de Teoria y Procesos del Diseno, \\ Diseno Ambiental, Universidad Autonoma Metropolitana Unidad Cuajimalpa, Torre III, 5to. piso, \\ Av. Vasco de Quiroga 4871, Col. Santa Fe Cuajimalpa, Del. Cuajimalpa, Mexico D.F. 11850, Mexico; \\ cheard@correo.cua.uam.mx \\ * Correspondence: rca@ier.unam.mx; Tel.: +52-777-362-0090 (ext. 38010) \\ + These authors contributed equally to this work.
}

Academic Editor: Guido Carpinelli

Received: 17 June 2015; Accepted: 22 January 2016; Published: 17 February 2016

\begin{abstract}
Two on step ahead wind speed forecasting models were compared. A univariate model was developed using a linear autoregressive integrated moving average (ARIMA). This method's performance is well studied for a large number of prediction problems. The other is a multivariate model developed using a nonlinear autoregressive exogenous artificial neural network (NARX). This uses the variables: barometric pressure, air temperature, wind direction and solar radiation or relative humidity, as well as delayed wind speed. Both models were developed from two databases from two sites: an hourly average measurements database from La Mata, Oaxaca, Mexico, and a ten minute average measurements database from Metepec, Hidalgo, Mexico. The main objective was to compare the impact of the various meteorological variables on the performance of the multivariate model of wind speed prediction with respect to the high performance univariate linear model. The NARX model gave better results with improvements on the ARIMA model of between $5.5 \%$ and $10.6 \%$ for the hourly database and of between $2.3 \%$ and $12.8 \%$ for the ten minute database for mean absolute error and mean squared error, respectively.
\end{abstract}

Keywords: wind speed prediction; NARX; ARIMA; multivariate analysis

\section{Introduction}

At the end of 2014, the worldwide installed wind energy generating capacity was 369,597 MW; Europe having 134,007 MW, of which Germany and Spain stood out with 39,165 and 22,987 MW, respectively. During 2015, 42\% of electric power in Denmark was generated from wind [1]. In the Asia-Pacific region, China had a reported capacity of 114,609 MW of a total of 141,964 MW. In North America, the reported U.S. installed capacity was 65,879 MW with the Mexican and Canadian installed capacities being 9694 and 2551 MW, respectively. In Latin America, Brazil was the leader, with 5939 MW of $8526 \mathrm{MW}$ total [2].

Onshore wind based power generation has reached the technological maturity of being competitive with the lowest cost power generation options in many places. For example in Mexico in 2012 installed capacity increased by 76\% with respect to the total installed wind energy generation capacity at the end of 2011 due to increasing exploitation of the intense resource in the state of Oaxaca. 
In Oaxaca in the corridor from La Venta to La Mata passing through La Ventosa, the annual average wind speed is over $9 \mathrm{~m} / \mathrm{s}$ at $30 \mathrm{~m}$ above ground level with a dominant wind direction of North-Northwest/North-Northeast $70 \%$ of the time [3]. These highly favorable intense wind conditions in Oaxaca represent an appreciable source of inexpensive renewable energy in addition to Mexico's large fossil fuel reserves, which makes its exploitation a priority.

In Mexico, the National Center for Energy Control (CENACE) is responsible for the dispatch control of energy for the National Electric System. CENACE uses an information system to prepare pre-dispatch strategies. This system takes into account: availability, derating, restrictions and other factors that affect the dispatch capacity of generating units, as well as the electricity demand forecast. These models are produced by CENACE. An hourly operation plan is essential for each unit [4]. Energy producers have a responsibility to provide forecasts of wind and net energy production to CENACE a day ahead.

Recently, a considerable number of wind speed prediction models have been developed using a range of methods, some simple and others combining various techniques. Cadenas and Rivera [5] have reported short-term wind speed forecasting in a region of Oaxaca using an artificial neural network (ANN) with a representative hourly time series for the site. The model showed good accuracy for energy supply prediction.

Salcedo-Sanz et al. [6] presented a hybrid model between a fifth generation mesoscale model (MM5) and a neural network for short-term wind speed prediction at specific points.

Cadenas et al. [7] analyzed and forecasted wind velocity in Chetumal, Quintana Roo, Mexico, with a single exponential smoothing method. The method was found to be good for wind forecasting when the field data had alpha values close to one.

$\mathrm{Li}$ and Shi [8] compared three artificial neural networks for wind speed forecasting. These were: adaptive linear element, back propagation and radial basis function. None of these outperformed the others on all of the metrics evaluated.

A new short-term hybrid method based on wavelet and classical time series analysis to predict wind speed and power was proposed by Liu et al. [9]. The mean relative error in multi-step forecasting using this method was smaller than that from classical time series and back-propagation network methods.

A wind speed forecasting model for three regions of Mexico was developed using a hybrid autoregressive integrated moving average technique (ARIMA-ANN) by Cadenas and Rivera [10]. Initially, the ARIMA models were used to generate wind speed forecasts for the time series. The resulting errors were used to build the ANN to account for the non-linear behavior that the ARIMA technique could not model. This reduced the errors. The results showed that the hybrid model produced higher accuracy wind speed predictions than those of the separate ARIMA and ANN models for all three sites.

Kavasseri and Seetharaman [11] used the fractional-ARIMA models to predict wind speed and power production one or two days ahead for North Dakota. Forecasting errors in wind speed and power were compared to the persistence model. Significant improvements were obtained.

Li et al. [12] presented a robust two-step method for accurate wind speed forecasting based on a Bayesian combination algorithm and three neural network models: an adaptive linear element network (ADALINE), back propagation (BP) and a radial basis function (RBF). The results were that the neural networks were not consistent for one hour ahead wind speed. However, the Bayesian combination method could always give adaptive, reliable and comparatively accurate forecasts.

Liu et al. [13] evaluated the effectiveness of autoregressive moving average-generalized autoregressive conditional heteroscedasticity (ARMA-GARCH) for modeling mean wind speed and its volatility. The results showed that ARMA-GARCH could capture the trend changes of these parameters. In this study, it was found that none of the models were consistently better than the others over the whole range of heights considered. The authors recommended that for a given dataset, all of the models should be evaluated to find the most appropriate (Given that the range of heights 
considered was from 10 to $80 \mathrm{~m}$ and that the swept diameter of wind turbines is of the order of $90 \mathrm{~m}$ centered at a height of $70 \mathrm{~m}$ for 3-MW units, the heights covered by the study needed to be greater).

Guo et al. [14] developed an empirical mode decomposition (EMD) based feed-forward neural network (FFNN) learning model, which resulted in improved accuracy over each of the two methods individually for predicting daily and monthly mean wind speeds.

Liu et al. [15] have proposed hybrid ARIMA-ANN and ARIMA-Kalman methods for hourly wind speed forecasting. The authors concluded that both methods gave good results and can be applied to dynamic wind speed forecasting for wind power systems.

Kalman filtering was optimized for application to very short-term wind forecasting and applied to wind energy for a site at Varese Ligure in Italy by Cassola and Burlando [16]. A numerical meteorological model BOLAM (Bologna Limited Area Model) was used, and the results with the application of Kalman filtering showed a considerable reduction in error.

On the basis of parameter selection and data decomposition, two combined strategies and four modified models based on the first-order and second-order adaptive coefficient (FAC and SAC) were proposed by Zhang et al. [17] for wind speed forecasting in four different sites in China. It was shown that the approaches derived from the combined strategies obtained higher prediction accuracy than the individual FAC and SAC models at the four sampled sites.

A hybrid model based on the EMD and ANNs named EMD-ANN for wind speed prediction was proposed by Liu et al. [18]. The results were compared to an ANN model and an autoregressive integrated moving average model. These showed that the performance of the model was very good compared to the individual methods.

Two prediction methods were studied by Peng et al. [19] for short-term wind power forecasting on a wind farm. Three key factors were used in the models: temperature, wind speed and direction. One was an artificial neural network and the other a hybrid model based on physical and statistical methods. The hybrid model produced higher accuracy results than the individual ANN model.

Chen and Yu [20] developed a hybrid model that integrated a support vector regression (SVR)-based state-space model with an unscented Kalman filter (UKF). This was to predict short-term wind speed sequences. The results gave much better performance for both one step and multi-step ahead wind speed forecasts than support vector machine, autoregressive and ANNs.

Hocaoglu et al. [21] developed a model for the artificial prediction of wind speed data, from atmospheric pressure measurements using the hidden Markov models (HMMs) technique. The model accuracy was evaluated from Weibull distribution parameters. The relevance of the technique is in its use of an additional meteorological variable (atmospheric pressure).

Hocaoglu et al. [22] used the Mycielski algorithm for wind speed forecasting. The algorithm performs a prediction using the total exact history of the data samples. The basic idea of the algorithm was to search for the longest suffix string at the end of the data sequence that had been repeated at least once in the history of the sequence. It was concluded that the model was robust for different behaviors of wind speed patterns. Experimental results also showed that the model not only provided very consistent time variations in agreement with the actual measured data, but also provides accurate distribution model parameters for estimating the wind power potential of a region.

Of all of the models reviewed, only two use additional meteorological parameters other than wind speed, such as pressure and temperature.

In this work, wind speed forecasting for La Mata, Oaxaca, and Metepec, Hidalgo, was carried out using univariate and multivariate models. To achieve higher accuracy forecasts, wind speed models using non-linear auto-regressive exogenous (NARX) modeling were developed. This technique uses additional exogenous variables (i.e., other than wind speed) to generate more accurate forecasts with respect to ARIMA models solely based on wind speed time series. The meteorological variables used in this study were: wind speed and direction, solar radiation, temperature and pressure. In the generation of the NARX model, only solar radiation or relative humidity was used due to the results from a correlation study. 


\section{Experimental Data}

Two weather databases were used as sources of information to allow the wind speed prediction models to be tested under a range of conditions. The time series of the variables used in this analysis are shown in Figures 1-6.
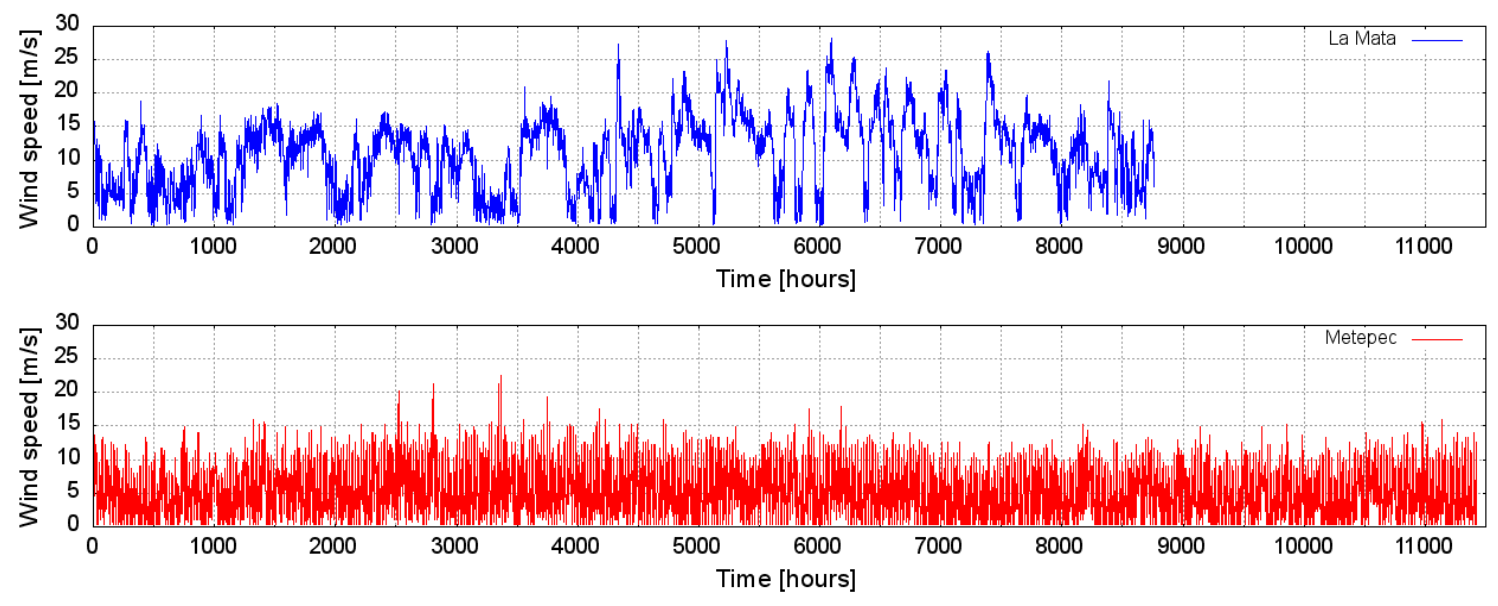

Figure 1. Wind speed time series from La Mata, Oaxaca (hourly averages), and Metepec, Hidalgo (ten-minute averages).

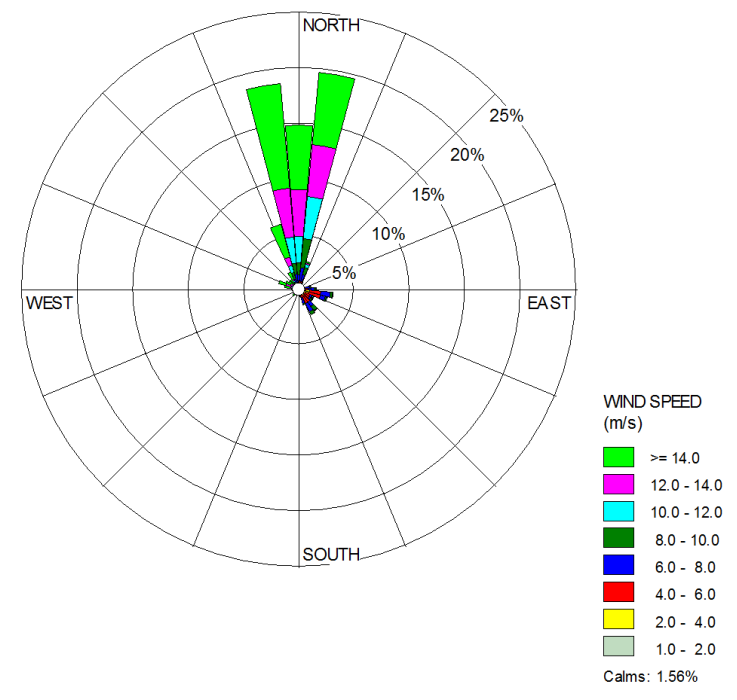

(a)

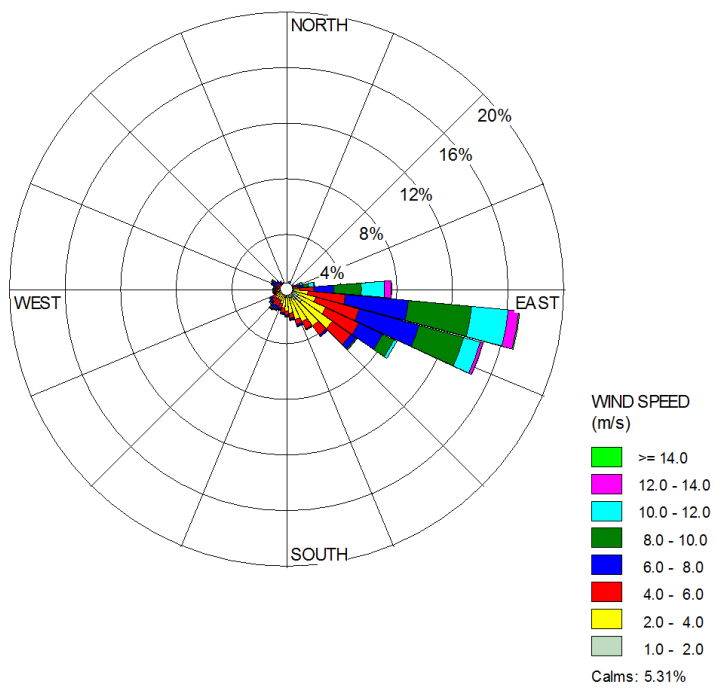

(b)

Figure 2. Wind rose of the studied sites. (a) La Mata, Oaxaca; (b) Metepec, Hidalgo.

One data set was from observations in the town of La Mata in the state of Oaxaca, Mexico. This was provided by the Mexican Federal Electricity Commission (Comision Federal de Electricidad (CFE)) and has 8759 data points corresponding to one year of hourly averaged measurements taken at $40 \mathrm{~m}$ above ground level from 1 May 2006 to 30 April 2007. The measurements were: wind speed, WS (m/s); wind direction, $\mathrm{WD}\left({ }^{\circ}\right)$; barometric pressure, $\mathrm{P}(\mathrm{mbar})$, air temperature, $\mathrm{T}\left({ }^{\circ} \mathrm{C}\right)$, and solar radiation, $\mathrm{SR}\left(\mathrm{W} / \mathrm{m}^{2}\right)$.

The other data set was from observations in the town of Metepec in the state of Hidalgo, Mexico. This was provided also by the CFE and has 68,550 data points which correspond to just over a year and three months of ten minutely averaged measurements. The measurements were made at a height 
of $50 \mathrm{~m}$ above ground level from 22 November 2007 to 12 March 2009. The measurements were: wind speed, WS $(\mathrm{m} / \mathrm{s})$; wind direction, $\mathrm{WD}\left({ }^{\circ}\right)$; barometric pressure, $\mathrm{P}(\mathrm{mbar})$, air temperature, $\mathrm{T}\left({ }^{\circ} \mathrm{C}\right)$, and relative humidity, $\mathrm{RH}(\%)$.

Figure 1 shows the measured wind speed for both stations. It can be appreciated that there are no tendencies for neither periodic nor seasonal wind speed variations in the time series. The average wind speeds are 10.9 and $5.2 \mathrm{~m} / \mathrm{s}$ for La Mata and Metepec, respectively.

Figure 2 shows the wind rose for both sites, where $0^{\circ}, 90^{\circ}, 180^{\circ}$ and $270^{\circ}$ denote North, East, South and West directions, respectively. In the case of La Mata, Oaxaca, the dominant wind direction is from the South (S). It should be noted that the wind direction is in the range from $335^{\circ}$ to $15^{\circ}$ for $59.4 \%$. Periods of calm $(<1 \mathrm{~m} / \mathrm{s})$ represent $1.56 \%$ of the total sample. In the case of Metepec, Hidalgo, the dominant wind direction is from West-Northwest (W-NW). It should be noted that $53.4 \%$ of the time the wind directions is in the range from $85^{\circ}$ to $135^{\circ}$. Periods of calm $(<1 \mathrm{~m} / \mathrm{s})$ represent $5.31 \%$ of the total sample.

Figures 3 and 4 show hourly average air temperature and barometric pressure, respectively, for both sites. The solar radiation series shown in Figure 5 for the La Mata site of course shows a daily cycle. The relative humidity for the Metepec site is shown in Figure 6.
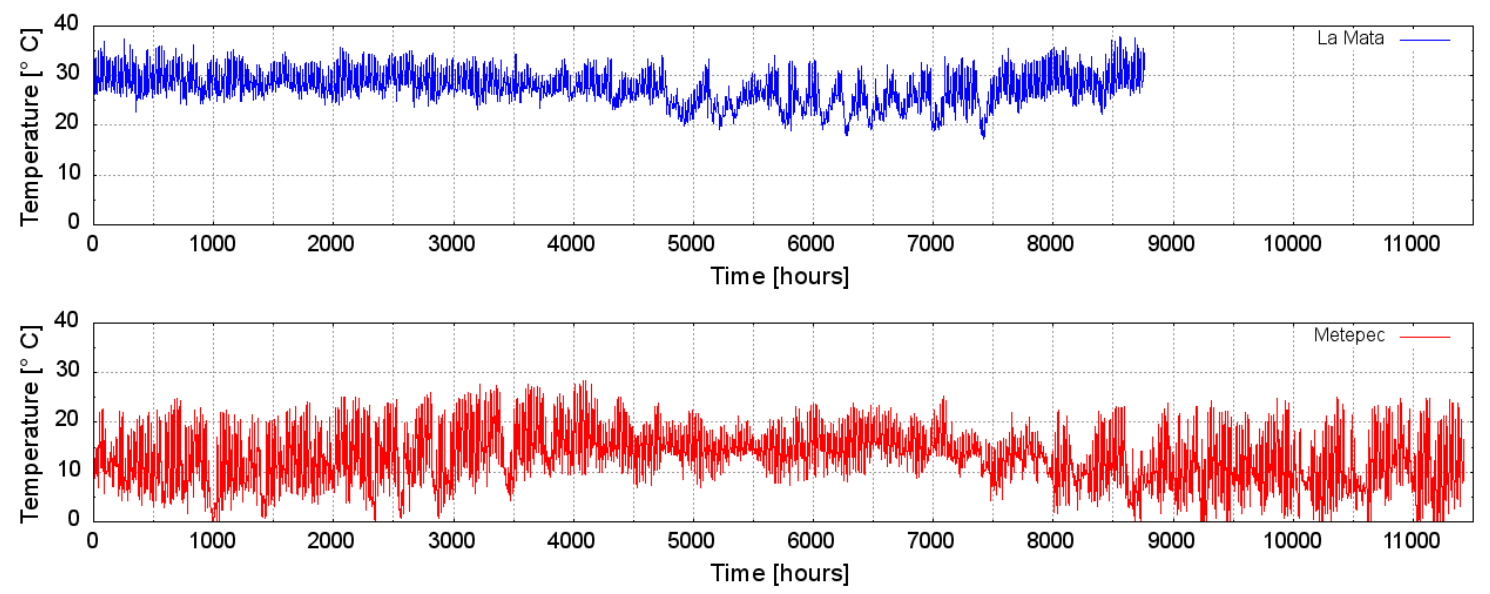

Figure 3. Air temperature time series from La Mata, Oaxaca (hourly averages) and Metepec, Hidalgo (ten-minute averages).
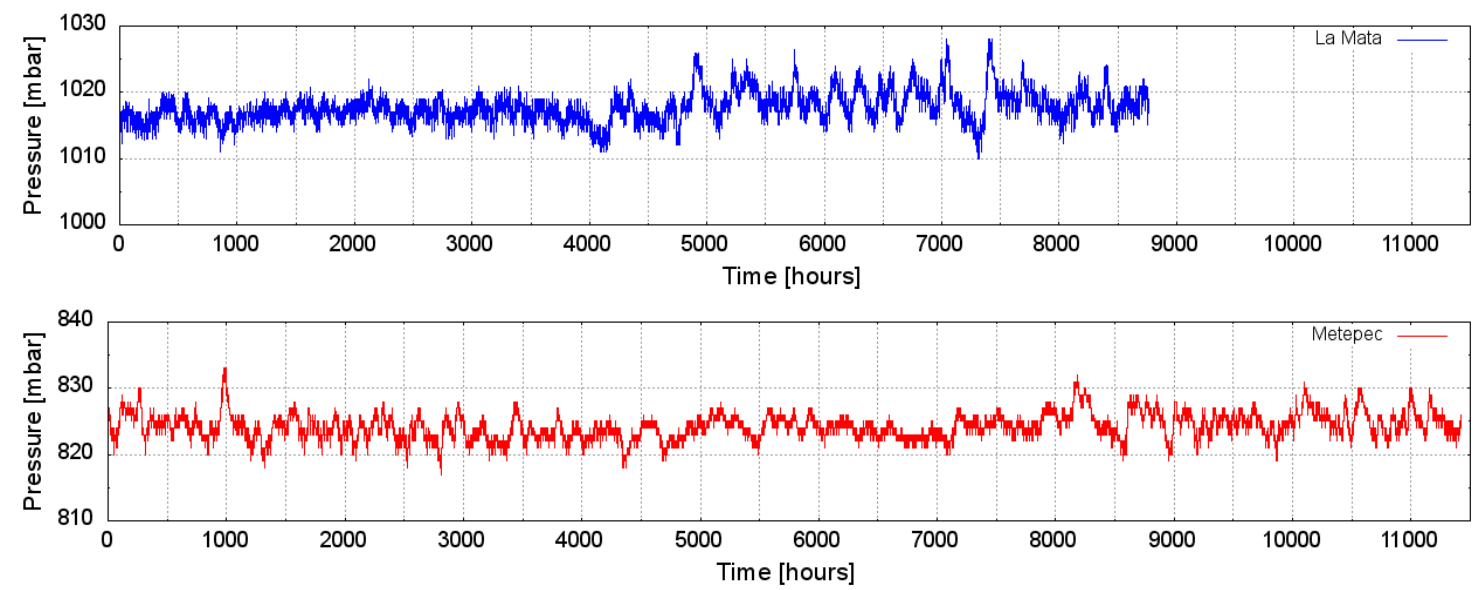

Figure 4. Barometric pressure time series from La Mata, Oaxaca (hourly averages), and Metepec, Hidalgo (ten-minute averages). 


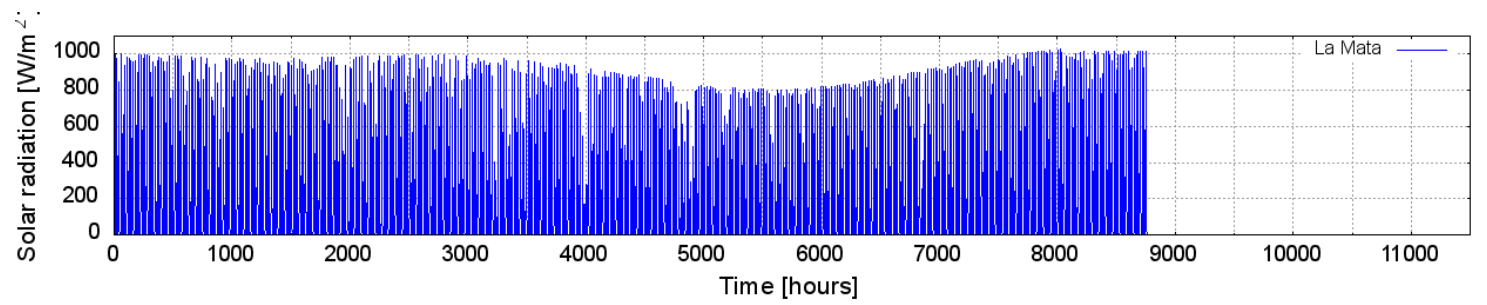

Figure 5. Solar radiation time series from La Mata, Oaxaca (hourly averages).

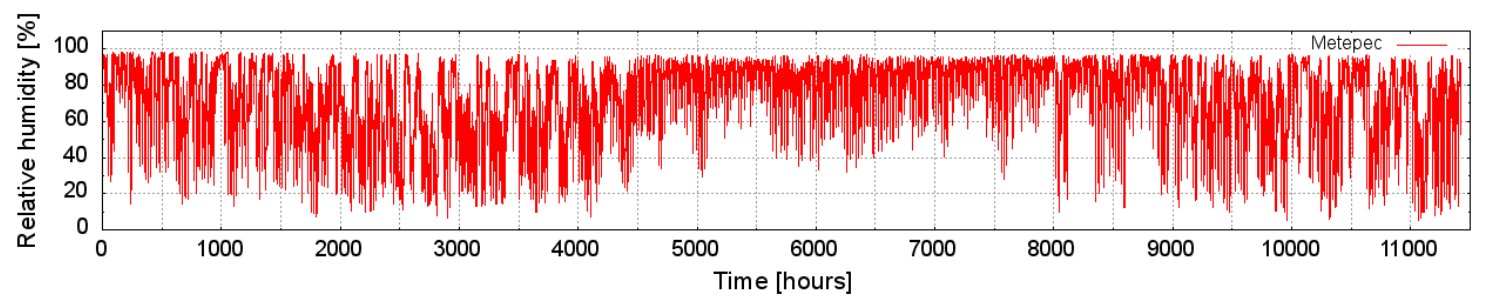

Figure 6. Relative humidity time series from Metepec, Hidalgo (ten-minute averages).

Tables 1 and 2 give the basic statistical characteristics (Central tendency and dispersion) for each of the measured variables for La Mata and Metepec respectively. The calculation of the mean wind direction and standard deviation requires special attention because the wind direction is a circular function resulting in a discontinuity $\left(0^{\circ}-360^{\circ}\right)$, so that the arithmetic mean cannot be used. Therefore, the mean wind direction was calculated using the arctangent function of the averages of the sine and cosine of the wind directions data.

Table 1. Descriptive statistics of the involved variables of La Mata. WS, wind speed; WD, wind direction; $\mathrm{T}$, temperature; $\mathrm{P}$, pressure; $\mathrm{SR}$, solar radiation.

\begin{tabular}{cccccc}
\hline Variable & Minimum & Maximum & Mean & Mode & Standard Deviation \\
\hline WS $(\mathrm{m} / \mathrm{s})$ & 0.4 & 28.3 & 10.9 & 13.6 & 5.5 \\
$\mathrm{WD}\left({ }^{\circ}\right)$ & 0 & 360 & 4.8 & 9.5 & 36.5 \\
$\mathrm{~T}\left({ }^{\circ} \mathrm{C}\right)$ & 17.3 & 37.9 & 27.6 & 27.2 & 3.4 \\
$\mathrm{P}(\mathrm{mbar})$ & 1010 & 1028 & 1017.6 & 1017 & 2.5 \\
$\mathrm{SR}\left(\mathrm{W} / \mathrm{m}^{2}\right)$ & 0 & 1026 & 249.6 & 0 & 332.7 \\
$\mathrm{RH}(\%)$ & - & - & - & - & - \\
\hline
\end{tabular}

Table 2. Descriptive statistics of the involved variables of Metepec. RH, relative humidity.

\begin{tabular}{cccccc}
\hline Variable & Minimum & Maximum & Mean & Mode & Standard Deviation \\
\hline WS $(\mathrm{m} / \mathrm{s})$ & 0.4 & 19.3 & 5.2 & 0.4 & 3.2 \\
WD $\left({ }^{\circ}\right)$ & 6.6 & 355.9 & 113.3 & 103.3 & 50.5 \\
T $\left({ }^{\circ} \mathrm{C}\right)$ & -2.4 & 28.3 & 13 & 11.7 & 5.3 \\
P $(\mathrm{mbar})$ & 817.2 & 833 & 824.2 & 824 & 2 \\
$\mathrm{SR}\left(\mathrm{W} / \mathrm{m}^{2}\right)$ & - & - & - & - & - \\
RH $(\%)$ & 5.7 & 98.4 & 71.2 & 92.8 & 22.3 \\
\hline
\end{tabular}

\section{Time Series Models}

A time series model $\left(y_{t}\right)$ reproduces the patterns of the prior movements of a variable over time and uses this information to predict its future movements. It is possible in this way to construct a simplified model of the time series that represents its randomness, so that it is useful for prediction [23].

The present study uses univariate and multivariate techniques for wind speed prediction. The univariate method employs an autoregressive integrated moving average (ARIMA) model with only 
the wind speed as a variable. The multivariate method uses a non-linear autoregressive exogenous (NARX) model using wind direction, air temperature, barometric pressure, solar radiation and relative humidity, in addition to wind speed.

Multivariate analysis allows simultaneous consideration of diverse datasets allowing optimal decisions to be made considering all of the information.

\subsection{Autoregressive Integrated Moving Average Models}

ARIMA models have been used in a great number of time series prediction problems, because they are robust, as well as easy to understand and implement. However, difficulties exist with atypical values influencing the estimation of future values. A further disadvantage of stochastic models is generally their high order.

In the early 1970s, ARIMA models were popularized by Box and Jenkins [24], their names being associated with general ARIMA models applied to time series analysis and forecasting.

There are many ARIMA models. The non-seasonal general model is known as $\operatorname{ARIMA}(p, d, q)$, where:

AR: $p=$ order of the autoregression of the model;

$\mathrm{I}: d$ = degree of differencing to make the model stationary;

MA: $q=$ order of the moving average aspect of the model.

The linear expression to define the above notation is:

$$
y_{t}=\sum_{i=1}^{p} \phi_{i} y_{t-i}+\sum_{j=1}^{p} \theta_{j} e_{t-i}+\epsilon_{t}
$$

where $\phi_{i}$ for the purpose of stabilizing the variance, $i$ is the $i$-th autoregressive parameter, $\theta_{j}$ is the $j$-th moving average parameter and $\epsilon_{t}$ is the error term at time $t$.

ARIMA models are used in a wide range of applications from engineering to economics. In cases such as the prediction of power demand, wind speed and stock market value behavior, that is things that can be represented as a time series with sufficient measurements, these can be modeled by this technique.

The Box-Jenkins method was followed to model the time series from La Mata and Metepec. This is basically a three-step iterative process: model identification, parameter estimation and diagnostic checking [24]:

1. Identification. Identification methods are approximate procedures applied to a dataset to find the kind of model worth further investigation. This involves determining suitable values for parameters $p$ and $q$ and determining the degree of differencing, $d$, to obtain stationarity. At this stage, graphs of the original and differenced time series together with their estimated autocorrelation and partial autocorrelation functions are useful tools.

2. Estimation. Having an initial model specification, its parameters are estimated from the maximum likelihood or conditional least squares methods. These are used iteratively starting from values estimated during the identification stage.

3. Diagnostic Checking. Having identified the model and estimated its parameters, diagnostic checks are used to reveal its inadequacies and indicate suitable improvements. Residuals and their autocorrelations are inspected. If the model is a good fit to the data, then the residuals would correspond to white noise and have very little autocorrelation.

Proposed ARIMA Models

As described above, in the Identification step, the data were differenced to obtain a stationary or trend-free series (Figure 7). A transformation of the original series was obtained to stabilize the mean and variance and to identify potential models from the autocorrelation function (ACF) and the partial autocorrelation function (PACF). At this stage of data preparation, it was determined whether or not it 
should be transformed to stabilize the variance. In the following Estimation step, the parameters in potential models were calculated, and suitable criteria were used to select the best model (Figure 8). Finally, ACF and PACF were used to test the residuals as the Diagnostic Checking stage. Normality and " $t$ " tests were applied to the residuals to find their closeness to white noise (Figures 9 and 10).

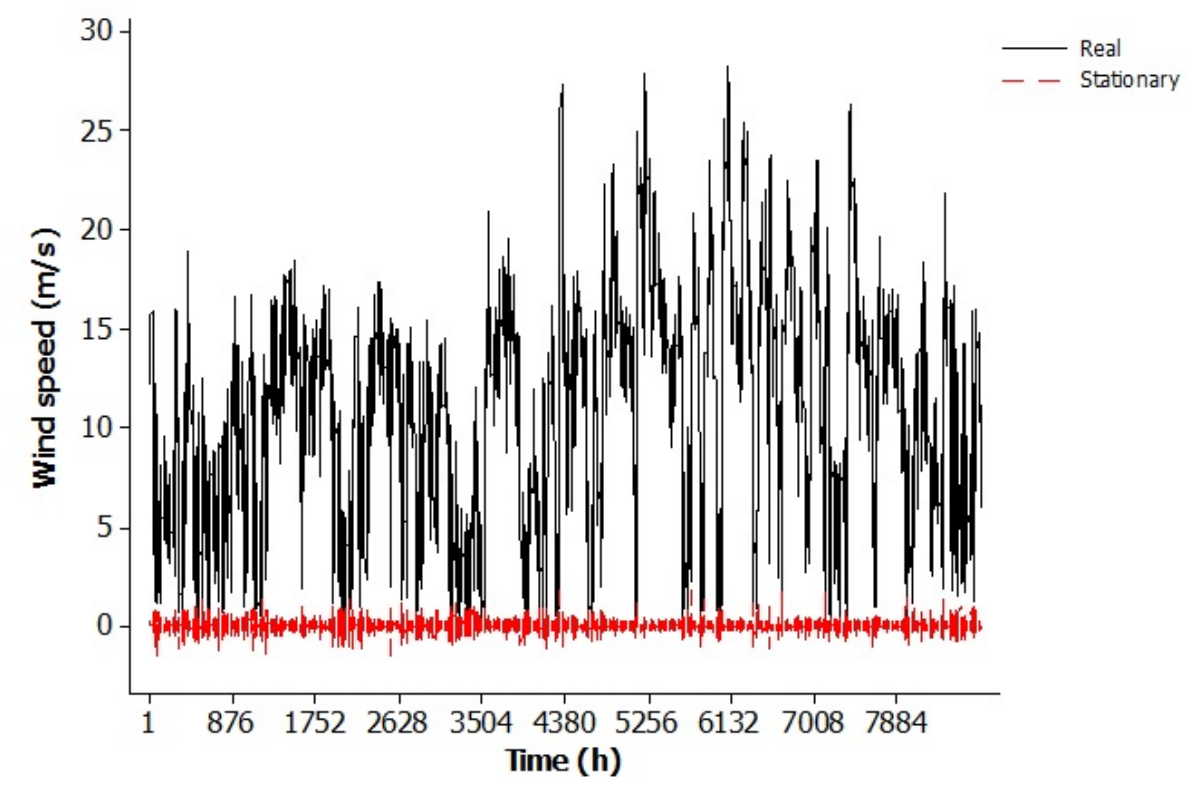

Figure 7. Real and stationary series from La Mata.

(with $\mathbf{5 \%}$ significance limits for the autocorrelations)

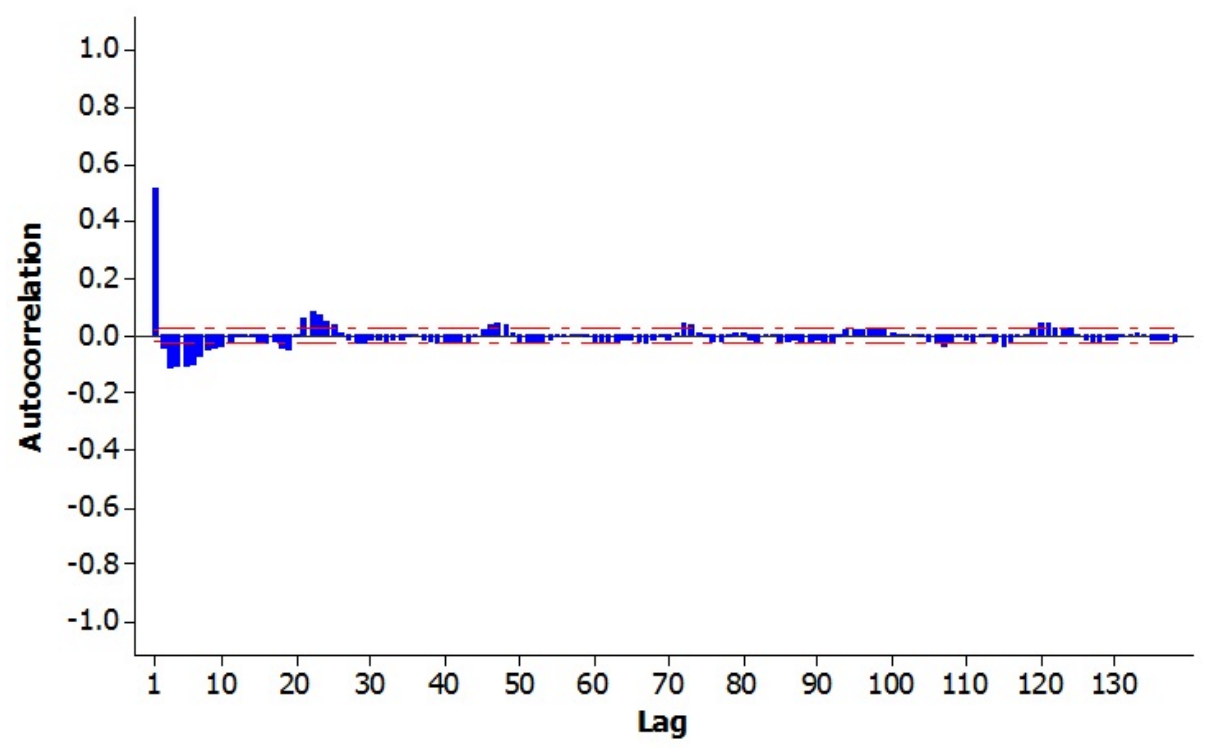

Figure 8. Autocorrelation function of the stationary series.

For La Mata and Metepec, the ARIMA models were $\operatorname{ARIMA}(1,1,0)$ and $\operatorname{ARIMA}(1,1,1)$, respectively. Table 3 shows the details of each of the two models. In the case of La Mata, the coefficient corresponding to the first term of equation: $1.1 y_{t-1}$ indicates the importance of the wind speed one hour earlier. This shows that the wind speed is persistent in this region. In the case of Metepec, the second term of the model apparently has a higher relevance: $0.6258 y_{t-2}$; however, the third term, the error coefficient $0.660 e_{t-1}$, which only involves a delay, has a similar order of magnitude. These two terms are thus of similar importance. 
Table 3. ARIMA models for the two studied sites.

\begin{tabular}{ccc}
\hline Site & $\operatorname{ARIMA}(p, d, q)$ & Model \\
\hline La Mata & $\operatorname{ARIMA}(1,1,0)$ & $y_{t}=1.1 y_{t-1}-0.1 y_{t-2}$ \\
Metepec & $\operatorname{ARIMA}(1,1,1)$ & $y_{t}=0.3742 y_{t-1}+0.6258 y_{t-2}+0.6601 e_{t-1}+e_{t}$ \\
\hline
\end{tabular}

Histograms of the residuals between the models and the measured time series for La Mata and Metepec are shown in Figures 9 and 10, respectively. The histograms show the form of the residuals distribution. It can be seen qualitatively that both cases are sharp normal distributions. The Metepec database has a lower scatter and higher frequencies because of the larger dataset. Both histograms are symmetrical, and this is borne out by the measures of central tendency, such as the mean, median and mode coinciding. This shows that there are no other patterns present in the data.

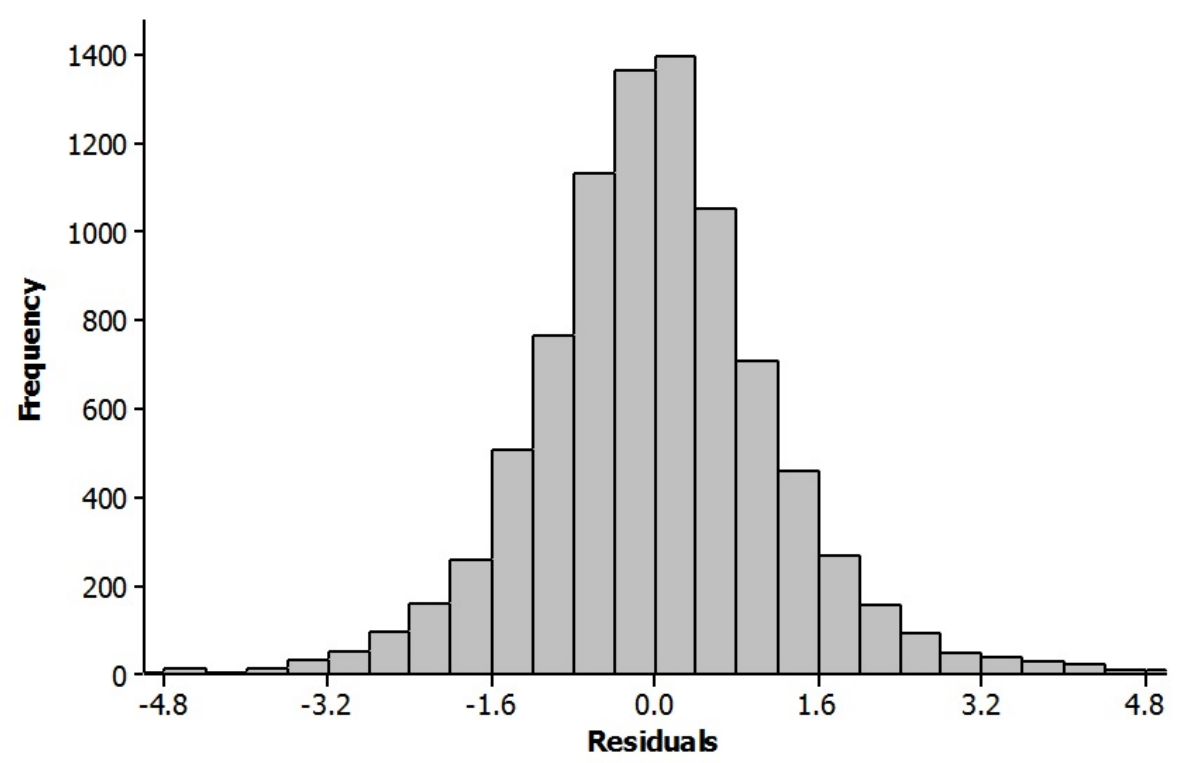

Figure 9. Error histogram for the ARIMA model in La Mata.

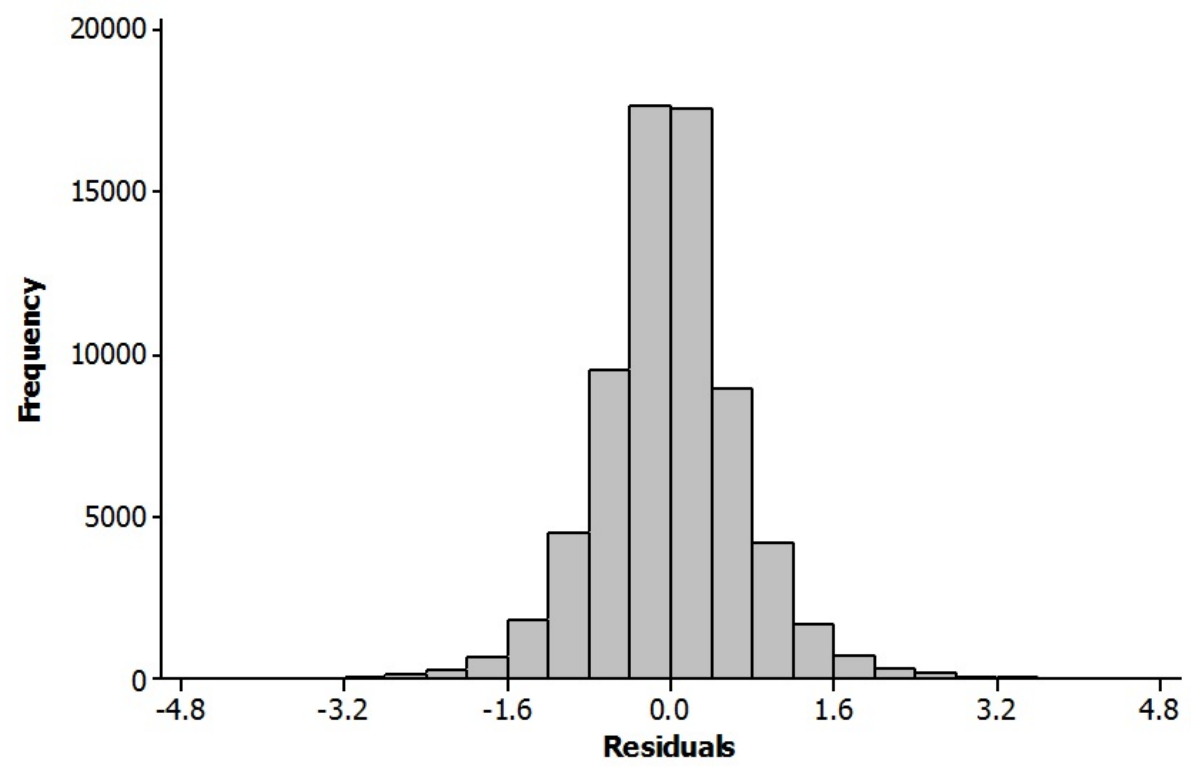

Figure 10. Error histogram for the ARIMA model in Metepec. 


\subsection{Nonlinear Autoregressive with Exogenous Inputs Models}

The NARX model is a type of dynamically-driven recurrent ANN. Recurrent networks have one or more feedback loops, which can be either local or global. Global loops reduce the computational memory requirements. There are two basic uses for recurrent networks:

1. associative memory;

2. input-output mapping networks.

Two applications of input-output are signal modeling and prediction in the form of time series. The most obvious advantage of the NARX models is that the same structure makes up different models and it thus has a reasonable computation cost. Thus, a NARX network can gain degrees of freedom when it includes a time period forecast as an input for subsequent periods compared to a feedforward network. This allows summary information of exogenous variables to be included, as well as a lesser number of residuals, which reduces the number of parameters that have to be estimated.

NARX networks have a more effective learning process compared to other types of neural networks (the learning gradient descent is better). These networks converge, and generalization is improved compared to other types of networks [25].

Figure 11 shows the simplest architecture for a NARX model. The model in this case has only one input, which represents the value of the exogenous variables, which in turn provides feed-forward to a $q$ number of delayed memory neurons. It has only one output $y(t+1)$, which represents the value of the predicted variable one step ahead. In other words, the output is one time unit ahead of the input. In turn, the output provides feedback to the network through a number of $q$ delayed memory neurons.

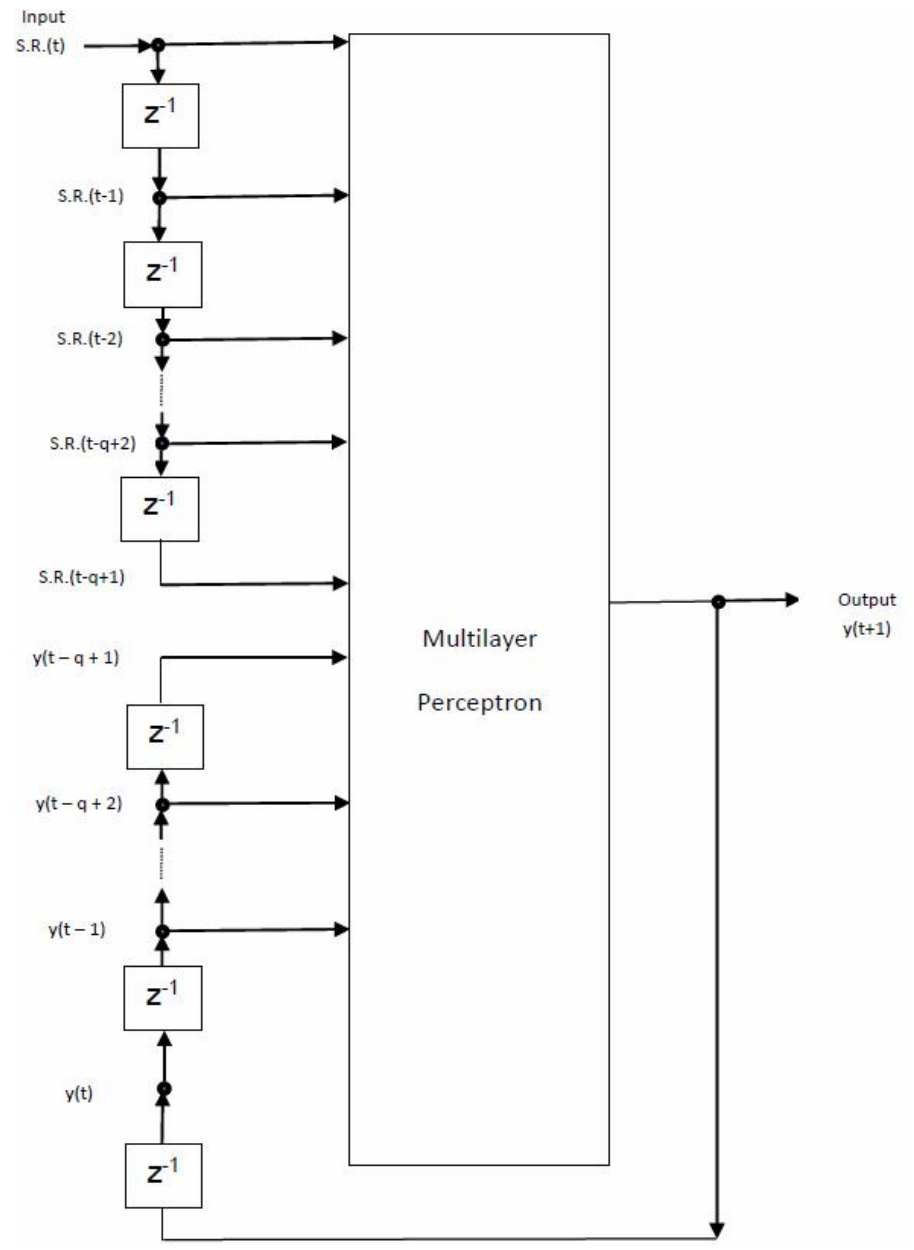

Figure 11. Architecture of the NARX. 
These two lines make up the input neural layer of a multilayer perceptron [26]. The following expression describes the model's dynamic behavior:

$$
y(n+1)=F(y(n), \cdots, y(n-q+1), u(n), \cdots, u(n-q+1))
$$

where $F$ is a nonlinear function of its arguments.

\subsubsection{Learning Algorithm for the NARX Network}

The neurons in the NARX models are sigmoid, and the performance function used in the training of the ANN is the mean squared error (MSE). For the NARX network, it is replaced as follows:

$$
\begin{gathered}
M S E=\frac{1}{n} \sum_{i=1}^{n}\left(e_{i}\right)^{2}=\frac{1}{n} \sum_{i=1}^{n}\left(t_{i}-y_{i}\right)^{2} \\
M S W=\frac{1}{n} \sum_{j=1}^{n}\left(W_{i}\right)^{2} \\
M S E_{\text {reg }}=\gamma \cdot M S E+(1-\gamma) \cdot M S W
\end{gathered}
$$

where: $t_{i}=$ target, $\gamma=$ performance ratio and MSW = mean squared weight.

This performance function results in smaller weights and biases in the network and, thus, makes the response smoother and less likely to over fit. The training function that updates the weights and bias values uses Levenberg-Marquardt optimization, which was modified to include the regularization technique [27].

\subsubsection{Proposed NARX Models}

The NARX model that had the best forecast performance used five input variables with two delays per variable. These were wind speed and direction, air temperature, barometric pressure and solar radiation (for La Mata) or relative humidity (for Metepec). There were ten hidden neurons. The final configuration is shown in Figure 12.

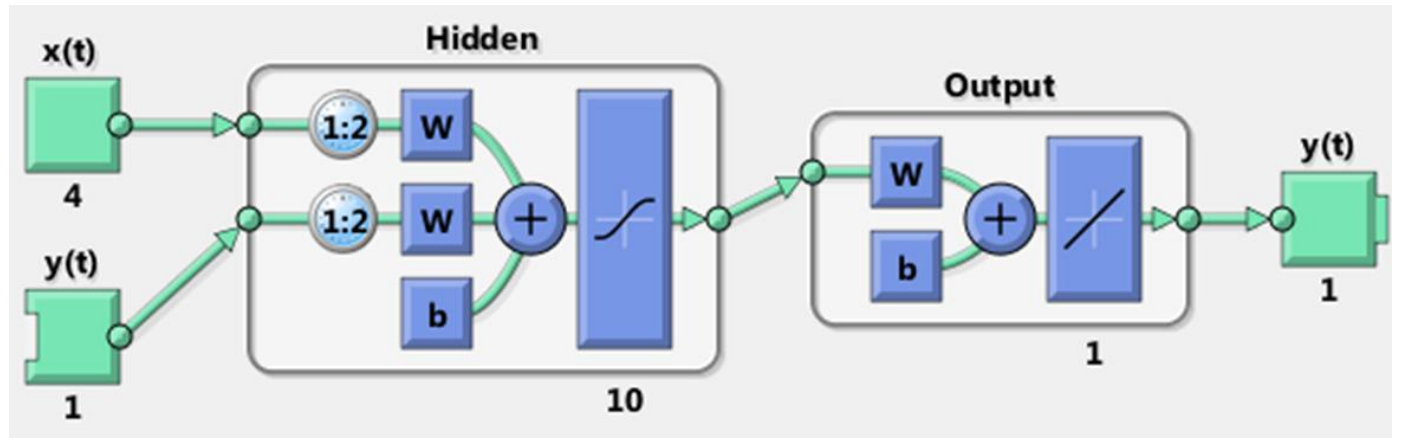

Figure 12. NARX generated in the MATLAB software.

\subsection{Statistical Error Measures}

The models' performance was evaluated via statistical error measurements. These were mean absolute error (MAE), mean squared error (MSE) and mean absolute percentage error (MAPE), described by the following expressions:

$$
M A E=\frac{1}{n} \sum_{t=1}^{n}\left|e_{t}\right|
$$




$$
M S E=\frac{1}{n} \sum_{t=1}^{n} e_{t}^{2}
$$

Hindcasts are a way of evaluating the difference between model results and measurements. The MAE is a measure of the average of the absolute error whose advantage is that it is easier for non-specialists to understand. MSE is similar, but the values are all positive due to the squaring; this makes it easier to use in an optimization technique [28]. To achieve a higher degree of certainty when comparing models, the MAPE was calculated by means of the percentage error $\left(P E_{t}\right)$ and the mean percentage error (MPE) using the following expressions:

$$
\begin{gathered}
P E_{t}=\left(\frac{Y_{t}-F_{t}}{Y_{t}}\right) \cdot 100 \\
M P E=\frac{1}{n} \sum_{t=1}^{n} P E_{t} \\
M A P E=\frac{1}{n} \sum_{t=1}^{n}\left|P E_{t}\right|
\end{gathered}
$$

The MAPE makes the comparison of results between from the two models easier because it is percentage based. This gives an indication of the size of the prediction errors in comparison to the measured values in the series.

\section{Wind Speed Forecasting Results}

Two different sites were selected to demonstrate the effectiveness of the methods proposed for wind speed forecasting and to verify the influence of other atmospheric variables besides wind speed on their accuracy. Each dataset was divided into three parts: 70\% for training, 15\% for validation and $15 \%$ for testing. Table 4 shows the details of these datasets.

Table 4. Datasets for the forecasting analysis.

\begin{tabular}{ccccc}
\hline Site & $\begin{array}{c}\text { Training Set } \\
\mathbf{( 7 0 \% )}\end{array}$ & $\begin{array}{c}\text { Validation Set } \\
\mathbf{( 1 5 \% )}\end{array}$ & $\begin{array}{c}\text { Testing Set } \\
\mathbf{( 1 5 \% )}\end{array}$ & $\begin{array}{c}\text { Total Data } \\
\mathbf{( 1 0 0 \% )}\end{array}$ \\
\hline La Mata & 6131 & 1314 & 1314 & 8759 \\
Metepec & 47,994 & 10,278 & 10,278 & 68,550 \\
\hline
\end{tabular}

To see how the prediction models fit to the real data, Figures 13 and 14 show the last $50 \mathrm{~h}$ of data allowing a qualitative comparison. These correspond to 50 data points for La Mata and 300 for Metepec. In these figures, the solid curve is the measured data, the long dashed curve is the ARIMA modeling and the shorter dashed curve is the NARX modeling. From these figures, the importance of the meteorological values of the previous time step (previous hour for La Mata and previous $10 \mathrm{~min}$ for Metepec) is obvious for one step ahead wind speed prediction, indicating the persistence of the wind speed on the short-term for these sites.

The mean absolute error and the mean squared error were used to quantitatively evaluate which model best predicts the wind speed behavior. Table 5 shows these measures of forecasting error. The improvement of the NARX model over the univariate ARIMA model based on the MAE and MSE results was calculated using the following equations:

$$
\begin{aligned}
P_{M A E} & =\left|\frac{M A E_{\text {ARIMA }}-M A E_{N A R X}}{M A E_{\text {ARIMA }}}\right| \cdot 100 \\
P_{M S E} & =\left|\frac{M S E_{\text {ARIMA }}-M S E_{N A R X}}{M S E_{A R I M A}}\right| \cdot 100
\end{aligned}
$$




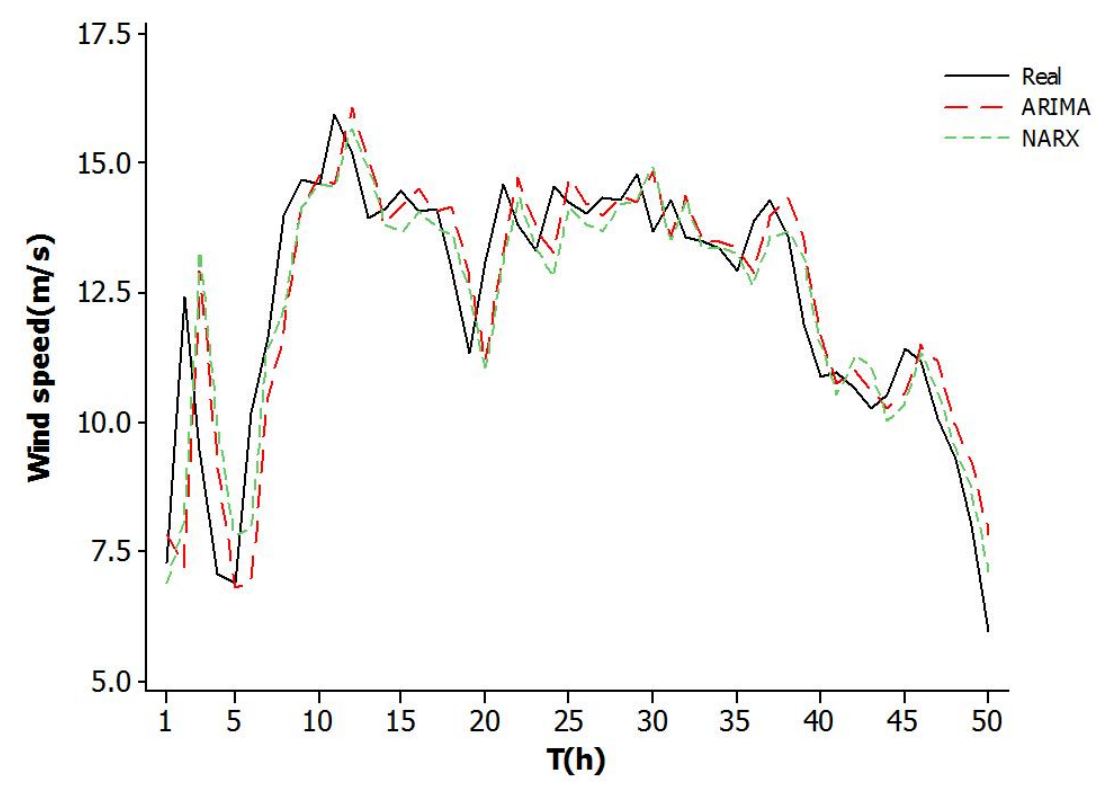

Figure 13. Qualitative comparison of wind speed forecasting for La Mata.

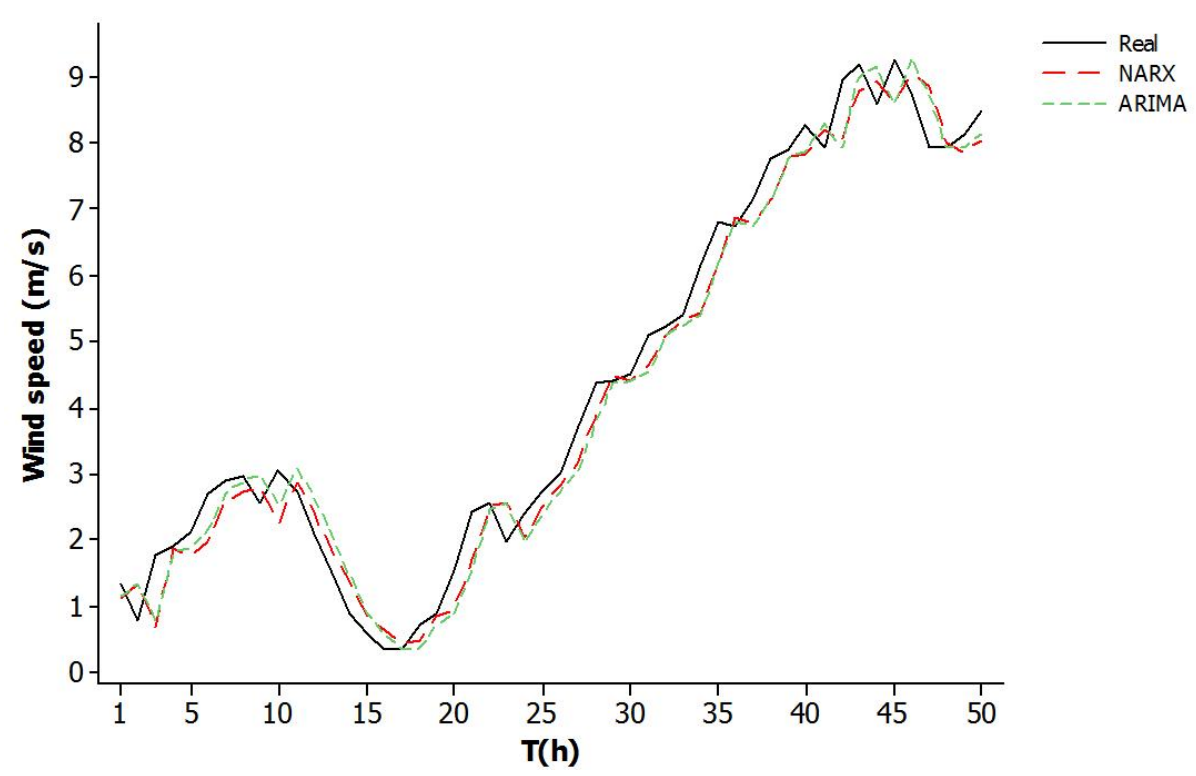

Figure 14. Qualitative comparison of wind speed forecasting for Metepec.

Table 5. Statistical errors generated by the ARIMA and NARX models.

\begin{tabular}{ccccc}
\hline \multirow{2}{*}{ Model } & \multicolumn{2}{c}{ La Mata } & \multicolumn{2}{c}{ Metepec } \\
\cline { 2 - 5 } & MAE & MSE & MAE & MSE \\
\hline ARIMA & 0.91 & 1.51 & 0.44 & 0.39 \\
NARX & 0.86 & 1.35 & 0.43 & 0.34 \\
Improved Percentages & $5.5 \%$ & $10.6 \%$ & $2.3 \%$ & $12.8 \%$ \\
\hline
\end{tabular}

From Figures 13 and 14, it can be seen that both models are effective, but it is not obvious which is the best. The error measures in Table 5 confirm the satisfactory performance of both models; however, it is clear that the NARX model is significantly better than the ARIMA model. The MAE of the NARX model for La Mata is 5.5\% better than the ARIMA model and $2.3 \%$ better for Metepec. The MSE 
percentage improvements are better than for MAE with values of $10.6 \%$ and $12.8 \%$ for La Mata and Metepec, respectively.

The additional information provided by more meteorological variables and the non-linear nature of the multivariate NARX model explain the superiority of this model.

\section{Conclusions}

A procedure to analyze and predict wind speed using standard meteorological variables was developed. Firstly, using traditional statistical techniques, such as the ARIMA model, and, secondly, by using a multivariate artificial neural network technique: the NARX model. Wind speed predictions given by both models were analyzed and compared qualitatively and quantitatively with measured data.

The results obtained show reasonable one step ahead wind speed prediction can be made with the univariate ARIMA model. However, by using a multivariate NARX model, more accurate results were obtained. The inclusion of additional meteorological variables is thus recommended in wind speed forecasting models if they are available.

As well as being a multivariate model, the NARX neural network is a class of discrete-time non-linear techniques that can represent a variety of non-linear dynamic systems, as in the case of wind speed time series.

Acknowledgments: We are thankful to Comision Federal de Electricidad (CFE) for allowing the use of the databases of the measurements of the variables used in this study.

Author Contributions: Erasmo Cadenas: Proposed the original idea for the paper, compiled the data bases, carried out the calculations for wind speed and wrote the original manuscript. Replied to referees' comments. Wilfrido Rivera: Proposed the original paper and contributed to the results analysis and discussion. Replied to referees' comments. Rafael Campos-Amezcua: Contributed to the compilation of the data bases, results analysis and discussion, the writing of the manuscript and replies to the referees' comments. Christopher Heard: Contributed to the writing of the manuscript and the improvement of the grammar and English style, the bibliographic review and replies to the referees' comments.

Conflicts of Interest: The authors declare no conflict of interest.

\section{References}

1. Denmark Broke World Record for Wind Power in 2015. Available online: http:/ /www.theguardian.com/ environment/2016/jan/18/denmark-broke-world-record-for-wind-power-in-2015 (accessed on 16 February 2016).

2. Global Wind Report. Annual Market Update, 2014; Global Wind Energy Council: Brussels, Belgium, 2015.

3. Cadenas, R.; Saldivar, G. Wind power plant La Venta II. Available online: http:/ / www.revista.unam.mx/vol.8/num12/art90/int90.htm (accessed on 16 February 2016).

4. Reglas de Despacho y Operacion del Sistema Electrico Nacional; Centro Nacional de Control de Energía: Mexico City, Mexico, 2001. (In Spanish)

5. Cadenas, E.; Rivera, W. Short term wind speed forecasting in La Venta, Oaxaca, México, using artificial neural networks. Renew. Energy 2009, 34, 274-278.

6. Salcedo-Sanz, S.; Perez-Bellidoa, A.; Ortiz-Garcia, E.; Portilla-Figueras, A.; Prieto, L.; Paredes, D. Hybridizing the fifth generation mesoscale model with artificial neural networks for short-term wind speed prediction. Renew. Energy 2009, 34, 1451-1457.

7. Cadenas, E.; Jaramillo, O.; Rivera, W. Analysis and forecasting of wind velocity in Chetumal, Quintana Roo, using the single exponential smoothing method. Renew. Energy 2010, 35, 925-930.

8. Li, G.; Shi, J. On comparing three artificial neural networks for wind speed forecasting. Appl. Energy 2010, 87, 2313-2320.

9. Liu, H.; Tian, H.; Chen, C.; Li, Y. A hybrid statistical method to predict wind speed and wind power. Renew. Energy 2010, 35, 1857-1861.

10. Cadenas, E.; Rivera, W. Wind speed forecasting in three different regions of Mexico, using a hybrid ARIMA-ANN model. Renew. Energy 2010, 35, 2732-2738. 
11. Kavasseri, R.; Seetharaman, K. Day-ahead wind speed forecasting using f-ARIMA models. Renew. Energy 2009, 34, 1388-1393.

12. Li, G.; Shi, J.; Zhou, J. Bayesian adaptive combination of short-term wind speed forecasts from neural network models. Renew. Energy 2011, 36, 352-359.

13. Liu, H.; Erdem, E.; Shi, J. Comprehensive evaluation of ARMA-GARCH(-M) approaches for modeling the mean and volatility of wind speed. Appl. Energy 2011, 88, 724-732.

14. Guo, Z.; Zhao, W.; Lu, H.; Wang, J. Multi-step forecasting for wind speed using a modified EMD-based artificial neural network model. Renew. Energy 2012, 37, 241-249.

15. Liu, H.; Tian, H.; Li, Y. Comparison of two new ARIMA-ANN and ARIMA-Kalman hybrid methods for wind speed prediction. Appl. Energy 2012, 98, 415-424.

16. Cassola, F.; Burlando, M. Wind speed and wind energy forecast through Kalman filtering of numerical weather prediction model output. Appl. Energy 2012, 99, 154-166.

17. Zhang, W.; Wu, J.; Wang, J.; Zhao, W.; Shen, L. Performance analysis of four modified approaches for wind speed forecasting. Appl. Energy 2012, 99, 324-333.

18. Liu, H.; Chen, C.; Tian, H.; Li, Y. A hybrid model for wind speed prediction using empirical mode decomposition and artificial neural networks. Renew. Energy 2012, 48, 545-556.

19. Peng, H.; Liu, F.; Yang, X. A hybrid strategy of short term wind power prediction. Renew. Energy 2013, 50, 590-595.

20. Chen, K.; Yu, J. Short-term wind speed prediction using an unscented Kalman filter based state-space support vector regression approach. Appl. Energy 2014, 113, 690-705.

21. Hocaoglu, F.; Gerek, O.; Kurban, M. A novel wind speed modeling approach using atmospheric pressure observations and hidden Markov models. J. Wind Eng. Ind. Aerodyn. 2010, 98, 472-481.

22. Hocaoglu, F.; Fidan, M.; Gerek, O. Approach for wind speed prediction. Energy Convers. Manag. 2009, 50, 1436-1443.

23. Burton, T.; Jenkins, N.; Sharpe, D.; Bossanyi, E. Wind Energy Handbook, 2nd ed.; John Wiley \& Sons, Inc.: Hoboken, NJ, USA, 2011.

24. Box, G.; Jenkins, G. Time Series Analysis: Forecasting and Control; Holden Day: San Francisco, CA, USA, 1970.

25. Gao, Y.; Er, M. NARMAX time series model prediction: Feedforward and recurrent fuzzy neural network approaches. Fuzzy Sets Syst. 2005, 150, 331-350.

26. Gardner, M.; Dorling, S. Artificial neural networks (the multilayer perceptron)-A review of applications in the atmospheric sciences. Atmos. Environ. 1998, 32, 2627-2636.

27. Diaconescu, E. Use of NARX neural networks to predict chaotic time series. WSEAS Trans. Comput. Res. 2008, 3, 182-191.

28. Makridakis, H.; Wheelwright, S. Forecasting Methods and Applications, 3rd ed.; John Wiley \& Sons, Inc.: Hoboken, NJ, USA, 1998.

(C) 2016 by the authors; licensee MDPI, Basel, Switzerland. This article is an open access article distributed under the terms and conditions of the Creative Commons by Attribution (CC-BY) license (http://creativecommons.org/licenses/by/4.0/). 